\title{
APLIKASI DIAGNOSIS PENYAKIT AYAM BROILER DENGAN SISTEM PAKAR MENGGUNAKAN METODE CERTAINTY FACTOR
}

\author{
Dwi Cahyo Kuncoro ${ }^{1}$, Ilhamsyah ${ }^{2}$ \\ ${ }^{1}$ Jurusan Rekayasa Sistem Komputer, Fakultas MIPA Universitas Tanjungpura \\ ${ }^{2}$ Jurusan Sistem Informasi, Fakultas MIPA Universitas Tanjungpura \\ Jalan Prof Dr. H. Hadari Nawawi Pontianak \\ Telp./Fax: (0561) 577963 \\ e-mail: ${ }^{1}$ cahyokun81@gmail.com. ${ }^{2}$ ilhamsyah@ sisfo.untan.ac.td
}

\begin{abstract}
ABSTRAK
Pengendalian terhadap penyakit ayam dilakukan oleh para peternak dengan mengetahui gejala awal penyakit yang terjadi. Selain penyakit ayam, kurangnya tenaga ahli di sekitar area peternakan menjadi masalah tersendiri bagi peternak. Kurangnya pengetahuan dan informasi yang dimiliki peternak mengenai penyakit yang menyerang ayam menyebabkan peternak terlambat untuk menangani penyakit. Penelitian ini membangun sebuah aplikasi sistem pakar diagnosis penyakit ayam broiler dengan sistem pakar menggunakan metode certainty factor yang akan membantu peternak untuk mendeteksi penyakit ayam broiler. Aplikasi sistem pakar yang dibangun berbasis web, metode certainty factor berfungsi memberikan nilai gejala terhadap penyakit dan nilai jawaban yang diperoleh dari seorang pakar. Keluaran yang dihasilkan aplikasi berupa jenis penyakit ayam broiler, faktor terjadinya penyakit dan cara penanganan penyakit. Pengujian aplikasi dilakukan dengan membandingkan data dari peternak meggunakan aplikasi dengan hasil diagnosa pakar sebanyak 30 sampel ayam, dari 30 data yang diuji 25 sampel ayam hasilnya sama dengan diagnosa pakar sedangkan 5 data uji berbeda dengan daignosa pakar. Sehingga nilai kemungkinan dalam mendiagnosa penyakit ayam broiler sebesar $83 \%$.
\end{abstract}

Kata kunci: certainty factor, penyakit ayam broiler, sistem pakar, diagnosa

\section{PENDAHULUAN}

Ayam broiler adalah ayam pedaging yang dapat dipanen antara 6 sampai 13 minggu dengan bobot mencapai $1.5 \mathrm{~kg}$ pada umur 6 minggu[1]. Ayam broiler merupakan ternak yang paling efisien menghasilkan daging dibandingkan ayam yang lain. Peternak sering menghadapi berbagai penyakit yang menyerang ayam saat berternak ayam broiler. Pengendalian terhadap penyakit ayam dilakukan sendiri oleh para peternak dengan mengetahui gejala awal penyakit yang terjadi. Namun kurangnya pengetahuan mengenai gejala penyakit pada ayam broiler menjadi kendala bagi peternak. Selain penyakit ayam, kurangnya tenaga ahli di sekitar area peternakan menjadi masalah tersendiri bagi petenak.

Kurangnya ilmu pengetahuan dan informasi oleh peternak mengenal penyakit yang menyerang ayam menyebabkan peternak terlambat untuk menangani penyakit. Penanganan yang terlambat terhadap penyakit dapat mempengaruhi pertumbuhan ayam secara optimal dan dapat mengakibatkan ayam mengalami kematian. Sistem pakar dibangun berdasarkan kemampuan dan pengetahuan yang diperoleh dari pakar penyakit ayam broiler, sedangkan metode Certainty Factor digunakan untuk membantu pakar penyakit ayam broiler dalam tingkat keyakinan dalam mendiagnosis penyakit ayam broiler.

Penelitian yang pernah dilakukan yaitu membuat sistem pakar diagnosa 
penyakit tanaman agribisnis menggunakan metode Certainty Factor. Penelitian ini memberikan informasi tentang hasil diagnosis jenis penyakit agribisnis berdasarkan gejala-gejala yang di derita dengan menjawab pertanyaan [2].

Adapun penelitian lainnya tentang Certainty Factor yaitu membangun sistem pakar diagnosis penyakit pada ibu hamil berbasis mobile dengan menggunakan metode Certainty Factor (CF)[3]. Sistem yang dibangun pada penelitian tersebut bertujuan untuk mendiagnosa penyakit pada ibu hamil berbasis mobile dan bahasa pemrograman yang digunakan dalam membangun sistem adalah PHP, HTML dengan database MySQL.

Selain itu penelitian tentang penyakit ayam yaitu sistem pakar diagnosa penyakit ayam berbasis web menggunakan metode Forward dan Backword Chaining[4]. Sistem yang dibangun memberikan informasi tentang hasil diagnosa penyakit ayam dengan menjawab pertanyaan yang diajukan oleh sistem.

Berdasarkan permasalahan tersebut, penelitian ini bertujuan untuk membangun aplikasi diagnosis penyakit ayam broiler dengan sistem pakar menggunakan metode Certainty Factor dengan mengunakan web, sehingga pengetahuan untuk mendiagnosis penyakit ayam broiler dapat disebarluaskan dengan peternak lain yang membutuhkan selama terhubung dengan internet. Aplikasi diagnosis penyakit ayam broiler memberikan pilihan jawaban tidak, kemungkinan kecil, kemungkinan besar, dan pasti sehingga memberikan alternatif jawaban dalam melakukan diagnosis dan diharapkan dapat memperbaiki tingkat keakuratan diagnosa penyakit ayam broiler.

\section{LANDASAN TEORI}

\subsection{Sistem Pakar}

Sistem pakar (expert system) adalah suatu sistem yang berusaha mengadopsi pengetahuan manusia untuk dimasukkan ke dalam komputer, agar komputer dapat menyelesaikan masalah seperti para ahli pada bidang tertentu[5]. Sistem pakar yang baik dirancang agar dapat menyelesaikan suatu permasalahan tertentu dengan meniru kerja dari para ahli, selanjutnya sistem akan mencoba memecahkan suatu permasalahan sesuai dengan kepakarannya.

Pada dasarnya sistem pakar diterapkan untuk mendukung suatu aktivitas pemecahan masalah. Aktivitasaktivitas pemecahan masalah antara lain: penggabungan pengetahuan (knowledge fusing), pembuatan desain (designing), perancangan (planning), prakiraan (forecasting), perumusan (prescribing), penjelasan (explaining), pemberian nasihat (advising) dan pelatihan (tutoring). Sistem pakar juga dapat menjadi asisten yang memiliki pengalaman maupun kemampuan dari seorang pakar. Sistem pakar menarik kesimpulan dengan basis pengetahuan yang sudah dimasukkan ke dalam komputer oleh seorang pakar. Kombinasi pengetahuan yang didapat dari satu atau lebih pakar akan digunakan dalam proses pengambilan keputusan untuk menyelesaikan masalah tertentu. Secara umum, sistem pakar merupakan sistem yang sudah diberi kemampuan dari sorang pakar ke dalam komputer sehingga komputer dapat menyelesaikan masalah sebagaimana yang dilakukan oleh seorang pakar.

Sistem pakar memiliki ciri-ciri yaitu terbatas pada kemempuan tertentu, dikembangkan secara bertahap oleh seorang pakar, memproses data berdasarkan aturan yang telah dibuat, dan keluaran bersifat anjuran. Manfaat yang dapat diambil dengan adanya sistem pakar yaitu memungkinkan orang awam bisa menggunakan komputer yang telah diberi keahlian dibidang tertentu tanpa keahlian langsung dari ahli atau pakar, menghemat waktu dalam mengambil keputusan, bisa melakukan proses secara terus-menerus, menyimpan pengetahuan dan keahlian dari seorang pakar, mampu beroperasi dalam lingkungan yang berbahaya, dan meningkatkan kualitas 
dengan memberi nasihat yang konsisten [6]. Struktur sistem pakar terdiri dari basis pengetahuan (knowledge base), basis data (data base). mesin inferensi (inference engine), dan antarmuka pemakai (user interface)[7].

\subsection{Certainty Factor}

Certainty Factor merupakan metode yang menggunakan bukti atau nilai dari seorang pakar untuk menyatakan kepercayaan dari sebuah kejadian (fakta atau hipotesis). Konsep Certainty Factor (CF) sering dikenal dengan adanya believe dan disbelieve. Believe merupakan keyakinan sedangkan disbelieve merupakan ketidakyakinan[8].

Certainty Factor digunakan untuk mengakomodasi pemikiran dari seorang pakar, biasanya dokter sering menganalisa suatu peyakit dengan mengungkapkan istilah seperti "mungkin" atau "kemungkinan besar". Untuk mengakomodasi hal tersebut maka digunakan Certainty Factor untuk monggambarkan tingkat keyakinan pakar terhadap masalah yang sedang dihadapi.

Metode yang dilakukan untuk mendapatkan nilai Certainty factor (CF) yaitu metode wawancara dari pakar/ahli. Nilai CF (Rule) didapat dari interpretasi "term" dari pakar yang dirubah menjadi nilai CF tertentu[7]. Nilai CF dapat dilihat pada tabel 1 .

Tabel 1 Tabel Certainty Factor

\begin{tabular}{|l|c|}
\hline \multicolumn{1}{|c|}{ Uncertain Term } & CF \\
\hline Definiteiv Not (Pasti tidak) & -1.0 \\
\hline $\begin{array}{l}\text { Almost Cerlainiy Not ( Hampit } \\
\text { Pasti Tidak) }\end{array}$ & -0.8 \\
\hline $\begin{array}{l}\text { Probably Not (Kcmungkinan } \\
\text { Besar Tidak) }\end{array}$ & -0.6 \\
\hline Maybe Not (Mungkin Tidak ) & -0.4 \\
\hline Unknow (Tidak Tahu) & -0.2 to \\
& 0.2 \\
\hline Maybe (Mungkin) & 0.4 \\
\hline Probably (Kemungkinan Besar) & 0.6 \\
\hline Almost Certainty (Hampir Pasti) & 0.8 \\
\hline Definitely (Pasti) & 1 \\
\hline
\end{tabular}

Berikut rumus yang akan digunakan dalam perhitungan didalam aplikasi:

1. Rumus Certainty Factor sequensial digunakan untuk menghitung antara jawaban peternak dengan nilai gejala terhadap penyakit terdapat pada persamaan 1.

IF E THEN H (CF Rule)

$\mathrm{CF}(\mathrm{H}, \mathrm{E})=\mathrm{CF}(\mathrm{E}) \times \mathrm{CF}($ Rule $)$

(1)

2. Setelah jawaban peternak dan nilai gejala tehadap penyakit sudah dihitung maka selanjutnya digunakan rumus kombinasi terdapat pada persamaan 2 .

$$
\mathrm{CF}\left(\mathrm{CF}_{1}, \mathrm{CF}_{2}\right)=\left\{\begin{array}{l}
\mathrm{CF}_{1}+\mathrm{CF}_{2}\left(1-\mathrm{CF}_{1}\right) \\
\text { jika } \\
\mathrm{CF}_{1}>0 \text { dan } \mathrm{CF}_{2}>0 \\
\\
\mathrm{CF}_{1}+\mathrm{CF}_{2}\left(1+\mathrm{CF}_{1}\right) \\
\mathrm{Jika} \\
\mathrm{CF}_{1}<0 \text { dan } \mathrm{CF}_{2}<0 \\
\\
\quad C F_{1}+C F_{2} \\
\hline 1-\min \left[\left|C F_{2}\right|,\left|C F_{2}\right|\right] \\
\text { jika } \\
\mathrm{CF}_{1}<0 \text { dan } \\
\mathrm{CF}_{2}>0 \text { atau } \\
\mathrm{CF}_{1}>0 \text { dan } \\
\mathrm{CF}_{2}<0
\end{array}\right.
$$

\section{METODE PENELITIAN}

Metode penelitian terdiri dari beberapa tahapan kerja yaitu studi literatur, observasi dan pengumpulan data, analisis kebutuhan, perancangan sistem, implementasi sistem, dan pengujian sistem. Tahap-tahapannya yaitu:

1. Studi Literatur

Pada tahap ini adalah studi kepustakaan yaitu pengumpulan bahanbahan referensi, literatur yang berupa data dari pakar yang berhubungan dengan penelitian, jurnal ilmiah, jurnal penelitian sebelumnya, buku-buku, artikel, dan data-data yang digunakan untuk mendukung tercapainya tujuan penelitian.

\section{Observasi dan Pengumpulan Data} Mengumpulkan data dan mempelajari teori yang berkaitan dengan metode Certainty Factor, penyakit ayam broiler, sistem pakar, Data Flow Diagram (DFD), Hypertext Preprocessor (PHP), dan web server. Literatur diperoleh dari berbagai sumber, mulai dari buku hingga literasi internet. 


\section{Analisis Kebutuhan}

Analisis kebutuhan dilakukan untuk megetahui suatu kondisi atau kebutuhan-kebutuhan yang harus dipenuhi. Tahap analisis kebutuhan dibagi menjadi tiga yaitu analisa data, analisa metode, dan analisa perangkat lunak.

Analisa data merupakan tahap yang penting untuk menunjang penelitian yang akan dilakukan. Sumber data diperoleh dari seorang pakar dokter hewan dari Dinas Pangan, Peternakan dan Kesehatan Hewan Provinsi Kalimantan Barat. Data yang diperlukan yaitu penyakit ayam broiler, faktor pendorong, cara penanganan penayakit, gejala penyakit ayam broiler dan nilai gejala terhadap suatu penyakit.

Analisa metode dilakukan untuk mengetahui metode yang dapat digunakan umtuk mendiagnosis jenis penyakit ayam broiler, sehingga dari hasil diagnosis dapat diketahui jenis penyakit ayam broiler. Metode yang digunakan yaitu metode Certainty Factor, dimana metode Certainty Factor dapat mengakomodasi pemikiran dari seorang pakar.

Perancangan sistem dimaksudkan untuk memperoleh tampilan diagnosis penyakit ayam broiler dengan sistem pakar menggunakan metode Certainty Factor secara keseluruhan hingga dicapai suatu aplikasi yang sesuai. Perancangan sistem terdiri dari perancangan model data, perancangan metode, dan perancangan perangkat lunak yang digambarkan dengan diagram konteks, Data Flow Diagram (DFD). Entity Relationship Diagram (ERD), dan perancangan antarmuka aplikasi.

4. Implementasi Sistem

Implementasi sistem merupakan tahapan setelah selesainya perancangan sistem. Pada tahapan implementasi ini, hasil rancangan akan dirubah menjadi suatu aplikasi dengan menggunakan bahasa pemrograman. Dengan adanya tahapan implementasi ini, metode atau algoritma yang diterapkan akan dapat mengelola data sehingga diperoleh hasil seperti yang diharapkan.

5. Pengujian Sistem

Pengujian aplikasi dilakukan untuk memastikan apakasi sistem yang telah dibangun berfungsi dengan baik sesuai dengan yang diharapkan. Apabila masih ada kesalahan maka akan dilakukan perbaikan sistem yang telah dibangun. Pengujian aplikasi dilakukan dengan menggunakan metode Black Box Testing. Metode black box testing merupakan pengujian untuk mengetahui apakah fungsi dari sistem aplikasi telah berjalan dengan semestinya sesuai dengan kebutuhan fungsional. Pengujian bisa dikatakan berhasil apabila fungsi-fungsi yang terdapat pada aplikasi dapat berfungsi dan hasil dari diagnosa sesuai dengan pakar.

\section{PERANCANGAN SISTEM}

4.1 Perancangan Model Data

Perancangan model data merupakan tahap yang penting dilakukan. Hal ini bertujuan agar nama penyakit, gejala penyakit dan nilai gejala terhadap penyakit dapat digunakan untuk menentukan sebuah penyakit dengan menggunakan metode Certainty Factor.

Data yang diperlukan pada penelitian ini sebagai berikut:

1. Data Penyakit Ayam Broiler

Penyakit ayam digunakan sebagai keluaran dari aplikasi yang dibangun. Data penyakit ayam dapat dilihat pada Tabel 2.

Tabel 2 Data Jenis Penyakit Ayam Broiler

\begin{tabular}{|c|l|c|}
\hline No & \multicolumn{1}{|c|}{ Penyakit pada ayam broiler } & Kode \\
\hline 1 & Aspergillosis & AP \\
\hline 2 & Salesma (Infectious Corvza) & SL \\
\hline 3 & $\begin{array}{l}\text { Batuk Menahun (Infectious Bronchitis) } \\
\text { BM }\end{array}$ & PKU \\
\hline 4 & $\begin{array}{l}\text { Penyakit Kantung Udara (Cronic } \\
\text { Respirator Dcscasci }\end{array}$ & MR \\
\hline 5 & Marex (Marex Disease) & \\
\hline
\end{tabular}

2. Data Gejala Penyakit Ayam Broiler

Gejala penyakit digunakan untuk membuat pertanyaan yang akan diajukan oleh sistem ke petenak. Data gejala 
penyakit dapat dilihat pada Tabel 3 .

Tabel 3 Gejala Penyakit Ayam Broiler

\begin{tabular}{|c|l}
\hline No & \multicolumn{1}{|c}{ Gejala Penvakit } \\
\hline 1 & Nafsu makan berkurang \\
\hline 2 & Nafas sesak. megap-megap \\
\hline 3 & Nafas ngorok \\
\hline 4 & Nafas cepat \\
\hline 5 & Bersm-bersm \\
\hline 6 & Tcrjadi kebutaan pada salah satu mata \\
\hline 7 & Batuk \\
\hline 8 & Badan Kurus \\
\hline 9 & Kelihatan mengantuk dan bulu berdiri \\
\hline 10 & Kedinginan \\
\hline 11 & Tampak lesu \\
\hline 12 & Muka pucat \\
\hline 13 & Sempoyongan \\
\hline 14 & Kelopak mata kemcrahan \\
\hline 15 & Pcrtumbuhan anak ayam terhambat \\
\hline 16 & Mata ayam membengkak \\
\hline 17 & Jengger ayam berwama kebiruan \\
\hline 18 & Keluar nanah dari mata dan berbau \\
\hline 19 & Terjadi pembengkakan dan sinius dan mata \\
\hline 20 & Kaki ayam pincang \\
\hline 21 & Sayap avam menggantung \\
\hline 22 & Ayam nampak membiru \\
\hline & \\
\hline
\end{tabular}

\subsection{Perancangan Perangkat Lunak} 4.2.1 Data Flow Diagram (DFD)

Perancangan perangkat lunak digambarkan dengan menggunakan DFD yang menggambarkan komponenkomponen sistem aplikasi diagnosis penyakit ayam broiler dan aliran-aliran data yang terdapat pada komponenkomponen tersebut.

1. DFD Level 0

DFD level 0 menggambarkan suatu proses desain sistem secara umum sehingga terlihat data yang mengalir pada masukan, proses dan keluaran. Aplikasi diagnosis penyakit ayam broiler ini melibatkan 3 entitas yaitu peternak, admin, dan pakar. Peternak hanya bisa melakukan diagnosa dengan menjawab semua pertanyaan yang diajukan oleh aplikasi, admin bertugas memasukkan, merubah maupun menghapus data-data seperti penyakit ayam, faktor pendorong, cara penanganan, gejala penyakit ayam dan nilai gejala terhadap suatu penyakit yang sudah diberikan oleh seorang pakar sedangkan pakar hanya dapat melihat data-data yang sudah dimasukkan oleh admin apakah sudah sesuai atau belum. Rancangan DFD level 0 dapat dilihat pada Gambar 2.

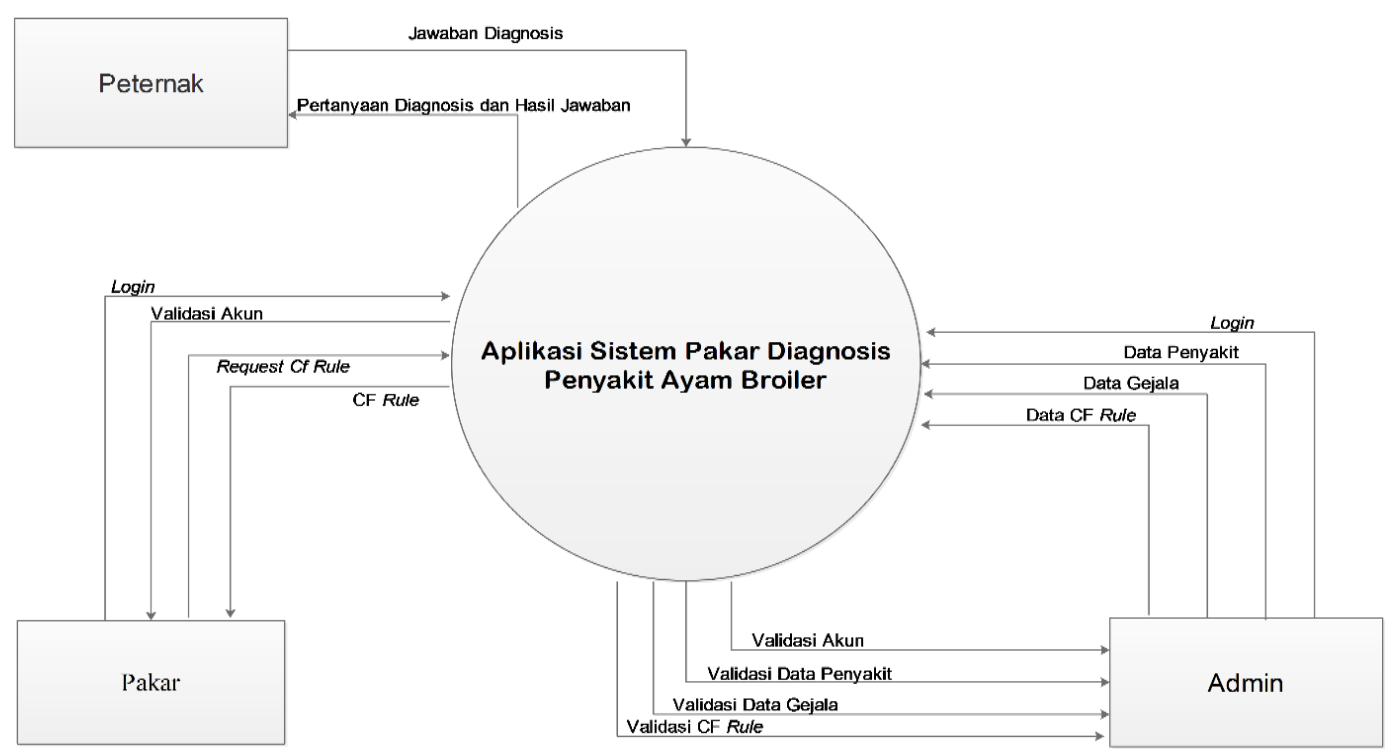

Gambar 2. DFD Level 


\section{DFD Level 1}

DFD level 1 merupakan penjabaran proses lebih lengkap dari DFD level 0 aplikasi diagnosis penyakit ayam broiler yang sebelumnya sudah dirancang. Terdapat 3 entitas yaitu peternak, admin dan pakar. Peternak hanya bisa melakukan diagnosi, admin memasukkan data nama penyakit, gejala penyakit, dan nilai $\mathrm{CF}$ rule gejala terhadap penyakit sedangkan pakar hanya bisa melihat data yang sudah dimasukkan oleh admin.

\subsubsection{Antarmuka Aplikasi}

1. Antarmuka Halaman Peternak

Halaman peternak merupakan halaman yang digunakan peternak untuk melakukan diagnosa pada aplikasi diagnosis penyakit ayam broiler dan menghasilkan keluaran nama penyakit. Halaman petenak dapat dilhat pada Gambar 3.
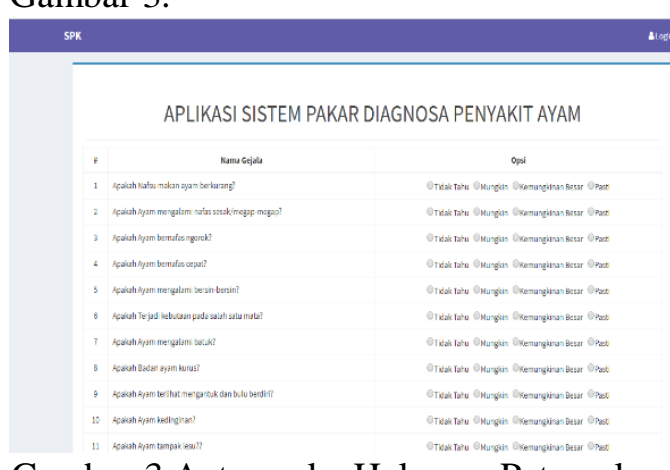

Gambar 3 Antarmuka Halaman Peternak

2. Antarmuka Halaman Penyakit

Penyakit Halaman penyakit digunakan admin untuk menambah, menyimpan, dan merubah nama penyakit ayam broiler. Halaman penyakit dapat dilihat pada Gambar 4.

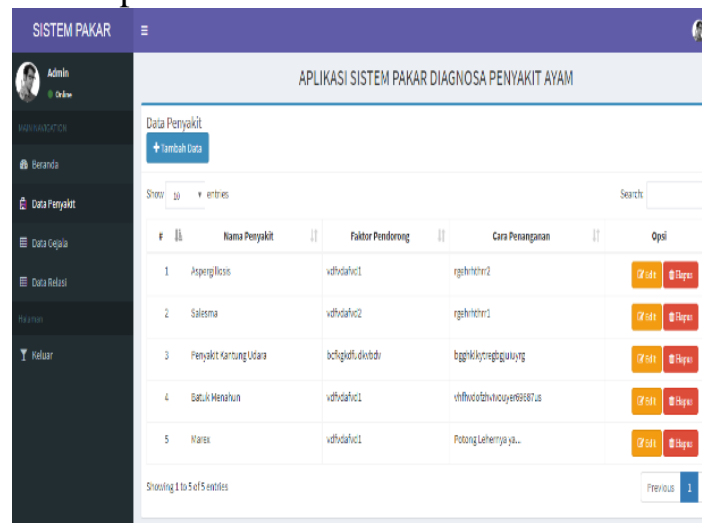

Gambar 4 Antarmuka Halaman Penyakit
3. Antarmuka Halaman Gejala

Halaman gejala digunakan oleh admin untuk menambah gejala, menyimpan, dan merubah gejala. Halaman gejala dapat dilihat pada Gambar 5.

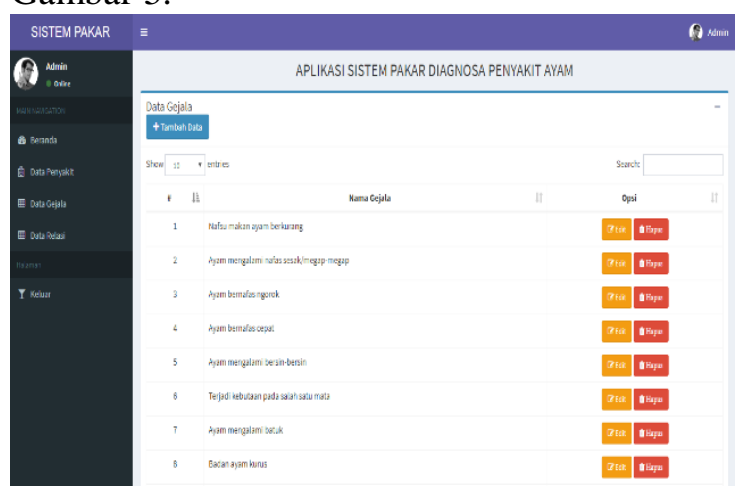

Gambar 5 Antarmka Halaman Gejala

4. Antarmuka Halaman Relasi

Halaman relasi digunakan oleh admin untuk memasukkan mlai gejala terhadap penyakit. Halaman relasi dapat dilihat pada Gambar 6.

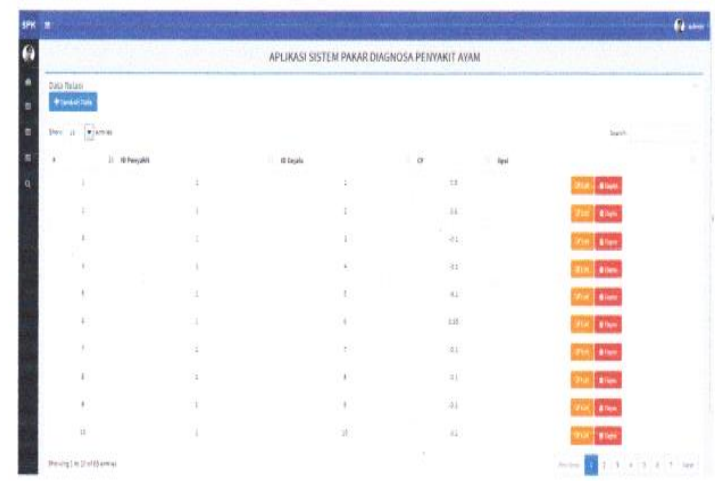

Gambar 6 Antarmuka Halaman Relasi

5. Antarmuka Halaman Pakar

Halaman pakar digunakan oleh pakar untuk melihat nilai gejala terhadap penyakit yang sudah dimasukkan oleh admin. Halaman pakar dapat dilihat pada Gambar 7.

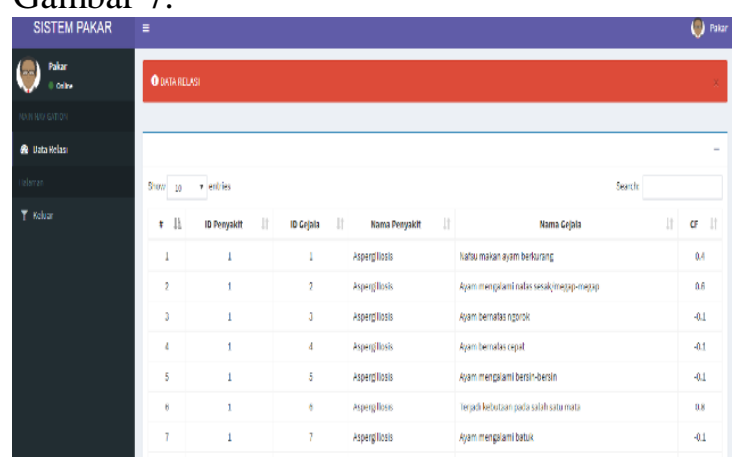

Gambar 7 Antarmuka Halaman Pakar 
Coding : Jurnal Komputer dan Aplikasi

Volume 08, No. 02 (2020). Hal 1-10

ISSN: $2338-493 \mathrm{X}$

\section{HASIL DAN PEMBAHASAN}

\subsection{Pengujian Aplikasi}

5.1.1 Implementasi Data dari Pakar ke Sistem Diagnosa

Implementasi data dari pakar ini menggunakan data yang berasal dari pakar dengan jumlah data sebanyak 15 data, pengujian keberhasilan implementasi data dari pakar ke sistem diagnosis penyakit ayam broiler dilakukan dengan menyamakan hasil diagnosa sistem dengan pakar. Implementasi data dari pakar ke sistem dapat dilihat pada Tabel 4.

Tabel 4 Implementasi Data dari Pakar ke Sistem Diagnosa

\begin{tabular}{|c|c|c|c|c|}
\hline No & Nama Gejala & $\begin{array}{c}\text { Penyakit } \\
\text { dari } \\
\text { Pakar }\end{array}$ & $\begin{array}{c}\text { Penyakit } \\
\text { Hasil } \\
\text { Diagnosis } \\
\text { Sistem }\end{array}$ & $\begin{array}{c}\text { Implemen } \\
\text { tasi } \\
\text { Kepakara } \\
\text { n }\end{array}$ \\
\hline \multirow{5}{*}{1} & $\begin{array}{l}\text { Terjadi kebutaan } \\
\text { pada salah satu } \\
\text { mata }\end{array}$ & \multirow{5}{*}{ 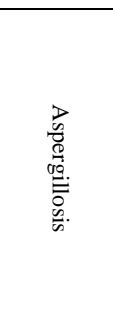 } & \multirow{5}{*}{ 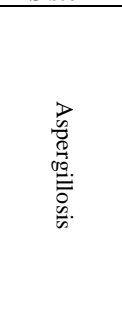 } & \multirow{5}{*}{ 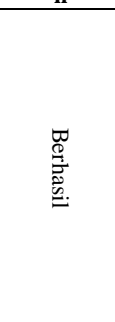 } \\
\hline & Tampak lesu & & & \\
\hline & $\begin{array}{l}\text { Mata ayam } \\
\text { membengkak }\end{array}$ & & & \\
\hline & $\begin{array}{ll}\text { Jengger } & \text { ayam } \\
\text { berwama } & \\
\text { kebiruan } & \\
\end{array}$ & & & \\
\hline & $\begin{array}{l}\text { Nafsu makan } \\
\text { berkurang }\end{array}$ & & & \\
\hline \multirow{3}{*}{2} & \begin{tabular}{|cc} 
Nafsu & makan \\
berkurang
\end{tabular} & \multirow{3}{*}{ 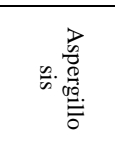 } & \multirow{3}{*}{ 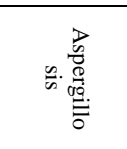 } & \multirow{3}{*}{ 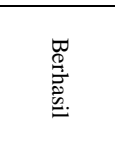 } \\
\hline & \begin{tabular}{|l} 
Tampak lesu \\
\end{tabular} & & & \\
\hline & \begin{tabular}{|l|} 
Jengger \\
berwama kebiruan
\end{tabular} & & & \\
\hline \multirow[t]{3}{*}{3} & $\begin{array}{l}\text { Nafas sesak } \\
\text { megap- megap }\end{array}$ & \multirow{3}{*}{ 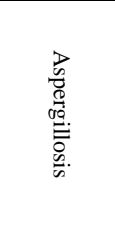 } & \multirow{3}{*}{ 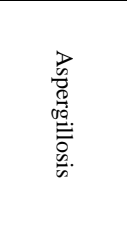 } & \multirow{3}{*}{ 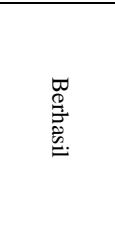 } \\
\hline & $\begin{array}{l}\text { Terjadi kebutaan } \\
\text { pada salah satu } \\
\text { mata }\end{array}$ & & & \\
\hline & $\begin{array}{l}\text { Mata ayam } \\
\text { membengkak }\end{array}$ & & & \\
\hline \multirow[t]{5}{*}{4} & $\begin{array}{l}\text { Nafsu makan } \\
\text { berkurang }\end{array}$ & \multirow{5}{*}{ 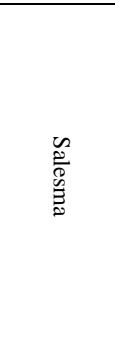 } & \multirow{5}{*}{ 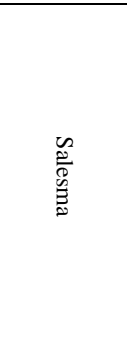 } & \multirow{5}{*}{ 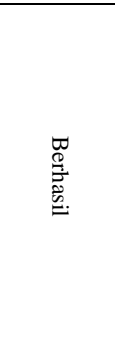 } \\
\hline & Bersin-bersin & & & \\
\hline & $\begin{array}{l}\text { Kelopak mata } \\
\text { kemerahan }\end{array}$ & & & \\
\hline & $\begin{array}{l}\text { Keluar nanah } \\
\text { dari mata dan } \\
\text { berbau }\end{array}$ & & & \\
\hline & $\begin{array}{l}\text { Terjadi } \\
\text { pembengkakan } \\
\text { dari sinus dan } \\
\text { mata }\end{array}$ & & & \\
\hline \multirow[t]{3}{*}{5} & Bersin-bersin & \multirow{3}{*}{ 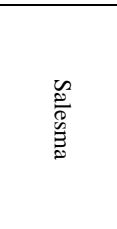 } & \multirow{3}{*}{ 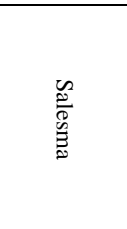 } & \multirow{3}{*}{ 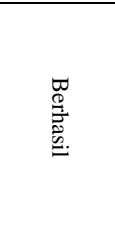 } \\
\hline & $\begin{array}{l}\text { Keluar nanah } \\
\text { dari mata dan } \\
\text { berbau }\end{array}$ & & & \\
\hline & $\begin{array}{l}\text { Terjadi } \\
\text { pembengkakan } \\
\text { dari sinus dan } \\
\text { mata }\end{array}$ & & & \\
\hline \multirow[t]{3}{*}{6} & $\begin{array}{l}\text { Nafsu makan } \\
\text { berkurang }\end{array}$ & \multirow{3}{*}{ 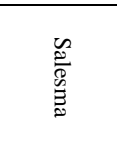 } & \multirow{3}{*}{ 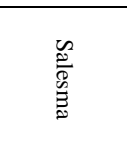 } & \multirow{3}{*}{ 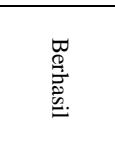 } \\
\hline & Bersin-bersin & & & \\
\hline & $\begin{array}{l}\text { Kelopak mata } \\
\text { kemerahan }\end{array}$ & & & \\
\hline 7 & $\begin{array}{l}\text { Nafsu makan } \\
\text { berkurang }\end{array}$ & $=-\infty \sigma$ & $=-\infty \varpi$ & 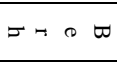 \\
\hline
\end{tabular}

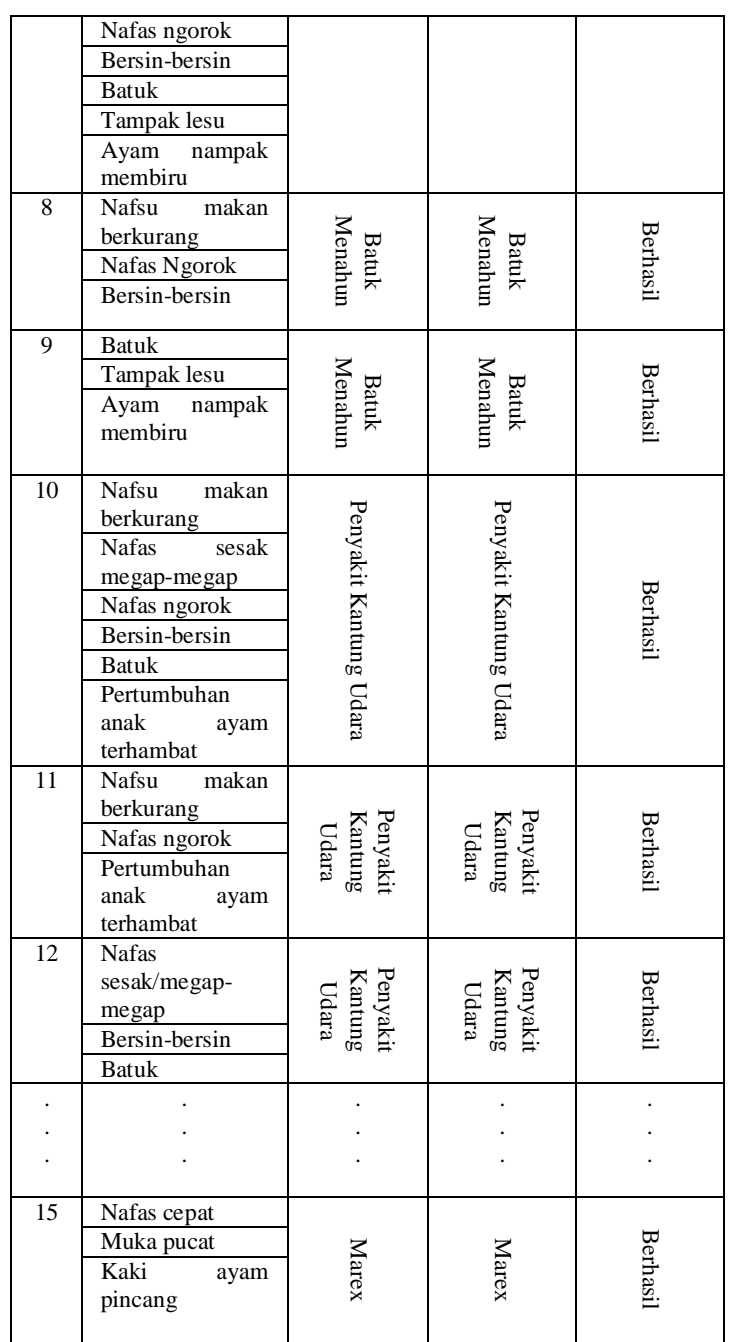

5.1.2 Pengujian Data dari Peternak

Pengujian data dari peternak menggunakan 30 data uji yang diperoleh dari peternak dengan mengguanakan aplikasi dan akan dibandingkan dengan hasil diagnosa dari pakar. Perbandingan pengujian sistem dapat dilihat pada Tabel 5 .

Tabel 5 Pengujian Sistem dengan Data dari Peternak

\begin{tabular}{|c|c|c|c|c|}
\hline No & $\begin{array}{c}\text { Sampel } \\
\text { Ayam }\end{array}$ & Gejala & $\begin{array}{c}\text { Diagnosa } \\
\text { Pakar }\end{array}$ & $\begin{array}{c}\text { Diagnosa } \\
\text { sistem }\end{array}$ \\
\hline \multirow{5}{*}{1} & \multirow{5}{*}{ Ayam 1} & Nafsu makan berkurang & \multirow{5}{*}{ Aspergillosis } & \multirow{5}{*}{ Aspergillosi } \\
\hline & & $\begin{array}{l}\text { Nafas sesak/megap- } \\
\text { megap }\end{array}$ & & \\
\hline & & Tampak lesu & & \\
\hline & & Jengger ayam berwama & & \\
\hline & & kebiru-biruan & & \\
\hline
\end{tabular}




\begin{tabular}{|c|c|c|c|c|c|c|c|c|c|}
\hline \multirow{6}{*}{2} & \multirow{6}{*}{ Ayam 9} & $\begin{array}{l}\text { Nafas sesak megap- } \\
\text { megap }\end{array}$ & \multirow{6}{*}{ Aspergillosis } & \multirow{5}{*}{ Aspergillosis } & \multirow{5}{*}{10} & \multirow{5}{*}{ Ayam 17} & $\begin{array}{l}\text { Terjadi kebutaan pada } \\
\text { salah satu mata }\end{array}$ & \multirow{5}{*}{ Salesma } & \multirow{5}{*}{ Salesma } \\
\hline & & Terjadi kebutaan pada & & & & & Tampak lesu & & \\
\hline & & salah satu mala & & & & & Mata ayam kemerahan & & \\
\hline & & $\begin{array}{l}\text { Kelopak mata ayam } \\
\text { kemerahan }\end{array}$ & & & & & $\begin{array}{l}\text { Keluar nanah dan mata } \\
\text { dan berbau }\end{array}$ & & \\
\hline & & $\begin{array}{l}\text { Mata ayam } \\
\text { membenokak }\end{array}$ & & & & & $\begin{array}{l}\text { Terjadi pembengkakan } \\
\text { dari sinus dan mata }\end{array}$ & & \\
\hline & & & & \multirow{7}{*}{ Aspergillosis } & \multirow{7}{*}{11} & \multirow{7}{*}{ Ayam 10} & Nafsu makan berkurang & \multirow{7}{*}{ Salesma } & \multirow{7}{*}{ Salesma } \\
\hline \multirow{6}{*}{3} & \multirow{6}{*}{ Ayam 24} & $\begin{array}{l}\text { Nafas sesak/megap- } \\
\text { megap }\end{array}$ & \multirow{6}{*}{ Aspergillosis } & & & & \begin{tabular}{|l|} 
Nafas cepat \\
\end{tabular} & & \\
\hline & & Bersin-bersin & & & & & Bersin-bersin & & \\
\hline & & Detsin-oetsin & & & & & Kelopak mata & & \\
\hline & & Mata ayam & & & & & kemerahan & & \\
\hline & & & & & & & Jengger berwama & & \\
\hline & & $\begin{array}{l}\text { Jengger ayam berwama } \\
\text { kebiru-biruan }\end{array}$ & & & & & kebiru-binian & & \\
\hline \multirow{4}{*}{4} & \multirow{4}{*}{ Ayam 4} & Nafsu makan berkurang & \multirow{4}{*}{ Aspergillosis } & \multirow{4}{*}{ Aspergillosis } & \multirow{5}{*}{12} & \multirow{5}{*}{ Ayam 5} & Nafsu makan berkurang & \multirow{5}{*}{ Salesma } & \multirow{5}{*}{$\begin{array}{c}\text { Penykit } \\
\text { kantung udara }\end{array}$} \\
\hline & & $\begin{array}{l}\text { Nafas sesak/megap- } \\
\text { megap }\end{array}$ & & & & & $\begin{array}{l}\text { Nafas sesak/megap- } \\
\text { megap }\end{array}$ & & \\
\hline & & Badan ayam kurus & & & & & Nafas cepat & & \\
\hline & & Ayam kedinginan & & & & & Bersin-bersin & & \\
\hline \multirow{5}{*}{5} & \multirow{5}{*}{ Ayam 2} & $\begin{array}{l}\text { Nafsu makan ayam } \\
\text { berkurang }\end{array}$ & \multirow{5}{*}{ Aspergillosis } & & & & $\begin{array}{l}\text { Kelopak mata } \\
\text { kemerahan }\end{array}$ & & \\
\hline & & Badan ayam kurus & & & & & Nafsu makan berkurang & & \\
\hline & & Ayam kedinginan & & Aspergillosis & & & Nafas ngorok & Batuk & Penyakit \\
\hline & & Tampak lesu & & & 13 & Ayam 7 & Batuk & menahun & kanrung udara \\
\hline & & $\begin{array}{l}\text { Jengger ayam berwama } \\
\text { kebiru-biruan }\end{array}$ & & & & & Ayam kurus & & \\
\hline & & Nafsu makan ayam & & & & & Nafsu ayam berkurang & & \\
\hline & & berkurang & & & 14 & Avam 16 & Bersin-bersin & Batuk & Batuk \\
\hline & & Nafas sesak'megap- & & & & & Tampak lesu & menahun & menahun \\
\hline 6 & Ayam 11 & megap & Aspergillosis & Aspergillosis & & & Ayam sempoyongaan & & \\
\hline & & Tampak lesu & & & . & . & . & . & . \\
\hline & & Jengger ayam berwama & & & . & . & . & . & . \\
\hline & & kebiru-biruan & & & & & Nafsu makan berkurang & & \\
\hline & & $\begin{array}{l}\text { Nafsu makan ayam } \\
\text { berkurang }\end{array}$ & & & & & $\begin{array}{l}\text { Nafas sesak megap- } \\
\text { megap }\end{array}$ & & \\
\hline 7 & $A=12$ & Bersin-bersin & Selocmo & Solormp & 30 & Avam 25 & Badan kurus & Marex & Marex \\
\hline$t$ & Ayam 13 & Muka ayam pucat & Salesma & Sälesma & & & Sempoyongan & & \\
\hline & & Keluar nanah dan mata & & & & & Pertumbuhan anak ayam & & \\
\hline & & dan berbau & & & & & terhambat & & \\
\hline & & Nafas sesak/megap- & & & & & Kaki pincang & & \\
\hline
\end{tabular}

\begin{tabular}{|c|c|c|c|c|}
\hline \multirow{5}{*}{8} & \multirow{5}{*}{ Ayam 29} & megap & \multirow{5}{*}{ Salesma } & \multirow{5}{*}{ Salesma } \\
\hline & & Bersin-bersin & & \\
\hline & & Mata ayam kemerahan & & \\
\hline & & Keluar nanah dan mata & & \\
\hline & & dan berbau & & \\
\hline \multirow{5}{*}{9} & \multirow{5}{*}{ Ayam 14} & $\begin{array}{l}\text { Nafas sesak/megap- } \\
\text { megap }\end{array}$ & \multirow{5}{*}{ Salesma } & \multirow{5}{*}{ Salesma } \\
\hline & & Bersin-bersin & & \\
\hline & & Mata ayam kemerahan & & \\
\hline & & $\begin{array}{l}\text { Mata ayam } \\
\text { membengkak }\end{array}$ & & \\
\hline & & $\begin{array}{l}\text { Keluar nanah dan mata } \\
\text { dan berbau }\end{array}$ & & \\
\hline
\end{tabular}

\subsection{Pembahasan}

Setiap penyakit dihitung dengan proses yang sama pada simulasi perhitungan certainty factor dengan nilai dari pakar, dari hasil perhitungan yang telah dilakukan akan didapatkan hasil masing-masing nilai dari penyakit yaitu penyakit Aspergillosis sebesar 0,70, peyakit Salesma sebesar 0.92, penyakit Batuk Menahun sebesar 0,77, penyakit Kantung Udara sebesar 0,89 dan penyakit Marex sebesar 0,93. Langkah untuk 
menjadikan nilai penyakit ke persentase yaitu menjumlahkan setiap nilai dari masing-masing penyakit sehingga totalnya menjadi 4,21 , selanjutnya nilai masing-masing dari setiap penyakit dibagi dengan 4,21 dan hasilnya dikali dengan $100 \%$ sehingga hasilnya penyakit Aspergillosis sebesar 16,62\%, peyakit Salesma sebesar 21,85\%, penyakit Batuk Menahun sebesar $18,29 \%$, penyakit Kantung Udara sebesar $21,14 \%$ dan penyakit Marex sebesar 22,09\%

Nilai yang terbesar dari masingmasing penyakit yang akan dijadikan keluaran oleh sistem. Berdasarkan hasil pengujian sistem, sistem yang dibangun dapat melakukan proses diagnosis penyakit ayam broiler dengan menjawab semua pertanyaan yang diajukan oleh sistem dan sistem akan menghasilkan keluaran berupa diagnosis nama penyakit, faktor penyebab terjadinya penyakit dan cara pencegahan penyakit. Jika salah satu pertanyaan tidak dijawab maka sistem tidak dapat memberikan hasil diagnosis penyakit. Pada implementasi data kepakaran ke sistem diagnosa dengan jumlah data sebanyak 15 menunjukkan hasil yang sama semua. Sedangkan pengujian data dari peternak menggunakan aplikasi dan dibandingkan dengan diagnosa dari pakar dengan data uji sebanyak 30 data uji, hasilnya adalah 25 data uji hasilnya sama dengan pakar sedangkan 5 data uji dengan hasil yang berbeda dengan persentase sebesar: $\frac{\text { data benar }}{\text { data keseluruhan }} \times 100 \%=$ $\frac{25}{30} \times 100 \%=83 \%$.

Perbedaan diagnosa antara pakar dan sistem terjadi karena pakar mendiagnosa dengan mempertimbangkan sebab akibat terjadinya suatu penyakit, faktor lingkukangan, dan gejala yang dialami ayam, sedangkan sistem mendiagnosa ayam hanya bertumpu pada gejala yang dimiliki.

\section{KESIMPULAN DAN SARAN \\ 6.1 Kesimpulan}

Berdasarkan penelitian yang telah dilakukan, diperoleh kesimpulan sebagai berikut:

1. Menentukan jenis penyakit yang digunakan untuk menjadi keluaran dari aplikasi maka dilakukan perhitungan terhadap masingmasing penyakit terlebih dahulu seperti yang terdapat pada simulasi perhitungan Certainty Factor, masing-masing penyakit mendapatkan nilai sebesar penyakit Aspergillosis sebesar $16,62 \%$, peyakit Salesma sebesar $21,85 \%$, penyakit Batuk Menahun sebesar 18,29\%, penyakit Kantung Udara sebesar 21,14\% dan penyakit Marex sebesar 22,09\% maka nilai yang terbesar yang akan dijadikan keluaran dari aplikasi.

2. Pengujian aplikasi dilakukan dengan membandingkan data dari peternak meggunakan aplikasi dengan hasil diagnosa pakar sebanyak 30 sampel ayam, dari 30 data yang diuji 25 sampel ayam hasilnya sama dengan diagnosa pakar sedangkan 5 data uji berbeda dengan daignosa pakar. Nilai kemungkinan dalam mendiagnosa penyakit ayam broiler dihitung berdasarkan hasil pengujian data dari peternak menggunakan aplikasi dan membandingkan dengan pakar hasilnya sebesar $\frac{\text { data benar }}{\text { data keseluruhan }} \times 100 \%=\frac{25}{30} \times 100 \%=$ $83 \%$.

\subsection{Saran}

Hal-hal yang menjadi saran untuk pengembangan aplikasi sistem pakar diagnosis penyakit ayam broiler menggunakan metode certainly factor agar menjadi lebih baik kedepannya adalah sebagai berikut:

1. Aplikasi sistem pakar diagnosis penyakit ayam broiler dapat diterapkan ke platfon mobile sehingga dapat di guanakan setiap saat.

2. Jumlah penyakit ayam broiler dapat ditambah lebih banyak lagi. 
Coding : Jurnal Komputer dan Aplikasi

Volume 08, No. 02 (2020). Hal 1-10

ISSN: 2338-493X

\section{DAFTAR PUSTAKA}

[1] Rasyaf, M. 2008. Panduan Beternak Ayam Pedaging. Jakarta: Penebar Swadava.

[2] Aryasa, Komang., 2018. Sistem Pakar Diagnosa Penyakit Agribisnis Menggunakan Metode Certainty Factor. Jurnal Informasi dan Teknologi Informasi Vol. 7, No 7, Halaman 54-67.

[3] Pangestika, Menur Wahyu. 2013. Sistem Pakar Untuk Diagnosa Penyakit Ibu Hamil Berbasis Mobile. Pontianak: Jumal Tugas Akhir Sistem Komputer Universitas Tanjungpura. Vol. 1.No. 1, Halaman 1-10.

[4] Riyadi, Lukman., 2016. Sstem Pakar Diagnosa penyakit Ayam Berbasis Web Menggunakan Metode Forward Dan Backword Chaining. Riau: Jurnal Tugas Akhir Sistem Informasi Universitas Islam Indragiri. Vol 5, No.3. Halaman 2935.

[5] Kusnni, (2006). Sistem Pakar, Teori dan Aplikasi. Yogyakarta: Andi Offset.

[6] Kusumadewi, S. (2006). Artificial intelligence: teknik dan Aplikasmya. Yogyakarta: Graha llmu

[7] Aziz, M. F. (1994). Pemrograman Sistem Pakar Jakarta: PT. Elex Media Komputindo

[8] Sutojo, T., Edy Mulyono, Vince Suhartono. 2010. Kecerdasan Buatan. Yogyakarta: Andi. 